\title{
Indigo and Bromo Indigo. The Plant and Animal Kingdoms
}

\author{
Fathi Habashi* \\ Department of Mining, Metallurgical, Materials Engineering, Laval University, Canada
}

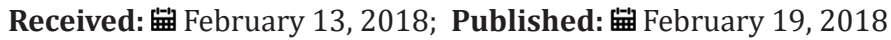

*Corresponding author: Fathi Habashi, Department of Mining, Metallurgical, Materials Engineering, Laval University, Quebec City, Canada, Tel: 418 651-5774; Email: Fathi.Habashi@arul.ulaval.ca

\begin{abstract}
Natural indigo was used since ancient times for dyeing textiles a blue color. Its structure became later known and has been synthesized by Adolf von Baeyer in 1880 in Germany who got the Nobel Prize in 1905. Bromo-indigo is a purple dye which was also used since ancient times by the Phoenicians in present day Lebanon and known as Tyrian purple obtained from the snails of Murex branderis in the Mediterranean Sea. Its structure became known in 1895 by Paul Friedlander an assistant to Baeyer. Incidentally bromine was discovered in sea weeds France in 1826 by Antoine Balard.
\end{abstract}

Keywords: Adolf von Baeyer; Paul Friedlander; Murex brandaris; Tyrian purple

\section{Introduction}

\section{Indigo}
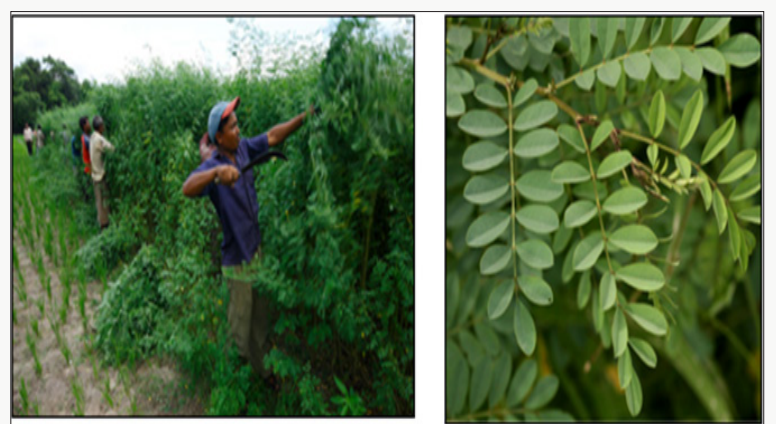

Figure 1: Indigo Plant.

Indigo has been known in India from remote periods of antiquity as indico and was called nila, meaning dark blue. The blue dye was obtained by steeping the plant leaves (Figure 1) in water to allow fermentation followed by the oxidation in air of the obtained solution. The precursor to indigo is indican; a colorless water-soluble glycoside readily hydrolyzes to release glucose and indoxyl (Figure 2). Oxidation by exposure to air converts indoxyl to indigo. The plant's leaves contain as much as $0.2-0.8 \%$ of indican. The precipitate from the fermented leaf solution was mixed with a strong base such as lye, dried, and powdered (Figure 3). Indigo is insoluble in water and to introduce it into fabric the dye must be reduced to a leuco form which is soluble in a dilute alkali solution. The fabric is immersed in this solution which allows the leuco compound to adhere to the fabric. The fabric is then exposed to air which oxidizes the leuco compound into the dye. By 1289, knowledge of the dye made its way to Europe, when the Venetian traveller Marco Polo reported on it. It began to be imported to Europe in 1516 by the way of Cape of Good Hope.

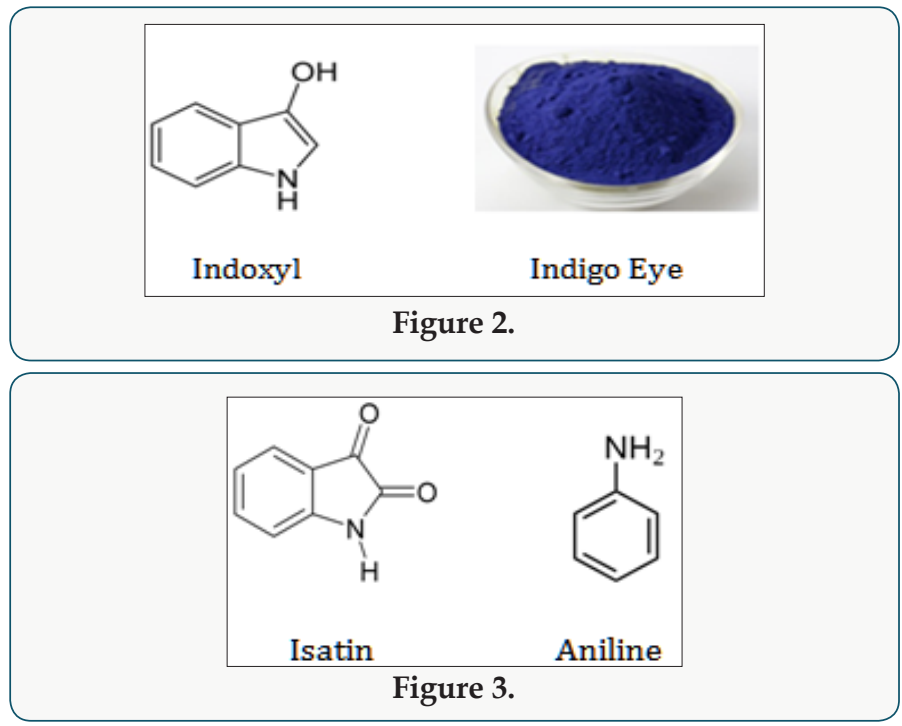


Many compounds like isatin was isolated by the oxidation of the natural product with nitric acid or aniline by the destructive distillation led to the knowing the structure of indigo. Indigo remained a rare commodity in Europe throughout the middle Ages till Adolf von Baeyer (1835-1917) (Figure 4) in 1880 at the University of Munich who got the Nobel Prize for synthesising indigo in 1905. The synthetic product put on the market in 1897 by the Badische Anilin- und Soda Fabrik in Ludwigshafen, Germany. It involves reacting o-nitrobenzaldehyde with acetone under highly basic conditions (Figure 5). The same indigo dye but in a lower concentration is also contained in the woad plant (Figure 5) known for a long time as the main source of blue dye in Europe. Woad was replaced by true indigo as trade routes opened up through Cape of Good Hope although laws were passed in some parts of Europe to protect the woad industry from the competition of the indigo trade.

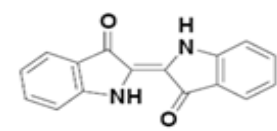

Indigo Structure

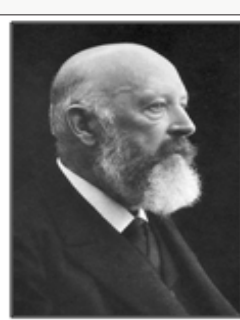

Adolf von Baeyer (1835-1917)
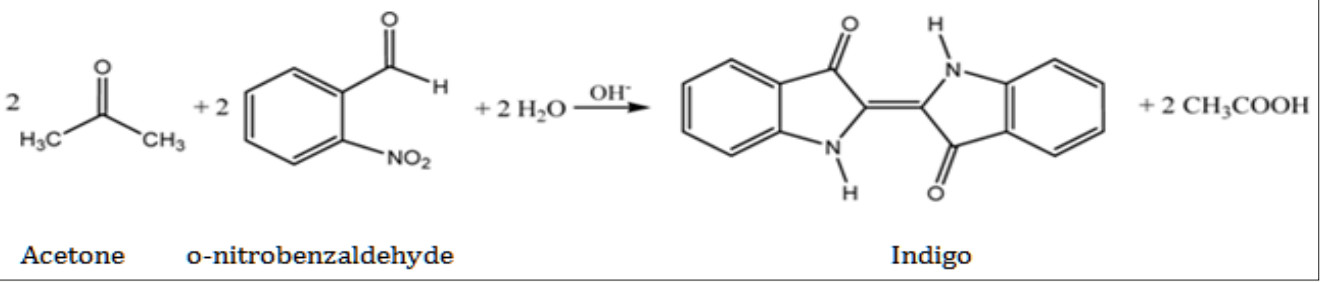

Figure 4: Synthesis of Indigo.

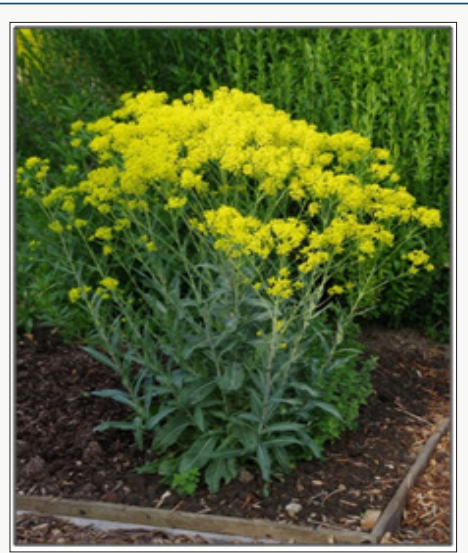

Figure 5: Woad plant.

\section{Tyrian Purple}

Fifteen hundred years before Christ, the people of Tyre of Phoenicia in present day Lebanon (Figure 6) produced a purple dye (Figure 7) from shell fish known as Murex brandaris (Figure 8). Tyre was a Phoenician island city founded around the third millennium $\mathrm{BC}$ and the word Phoenician is Greek is for dealers in purple. This dye was known as Tyrian purple. Today, piles of broken shell fish are seen outside the city (Figure 9). Paul Friedländer (1857-1923) was assistant to Baeyer in 1883 and in 1895 he accepted a position at the Technologische Gewerbemuseum in Vienna. During that time he discovered the thioindigo which is an organosulfur compound related to the plant-derived dye indigo, replacing two $\mathrm{NH}$ groups with two sulphur atoms (Figures 10-12). Friedländer isolated and analyzed the natural dyestuff of Tyrian purple. He was able to obtain 12,000 Murex brandaris from biologists working at the Mediterranean Sea. In a complicated process, he isolated $1.4 \mathrm{~g}$ of pure Tyrian purple. Contrary to his expectations, the compound did not contain sulphur, but was bromine substituted indigo.

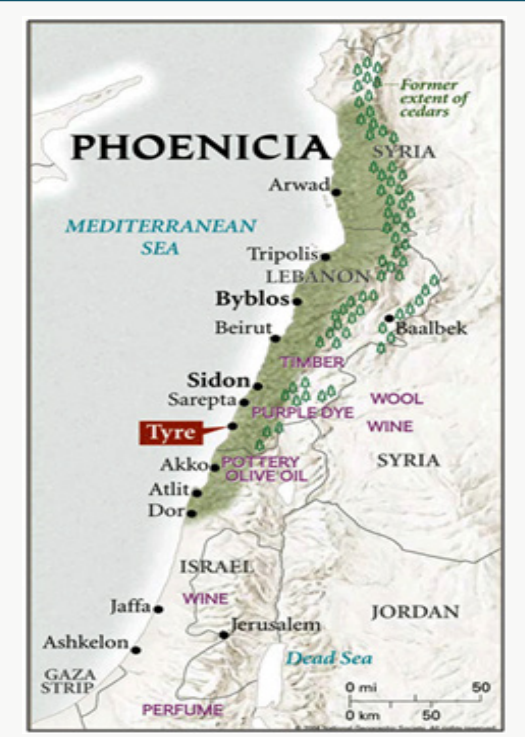

Figure 6: Tyre in Phoenicia- today's Lebanon. 


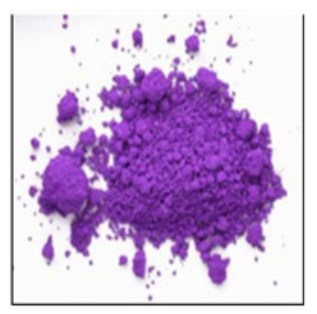

Figure 7: Tyrian Purple.

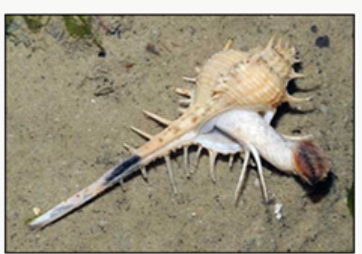

Figure 8: Snail of Murex Brandaris.

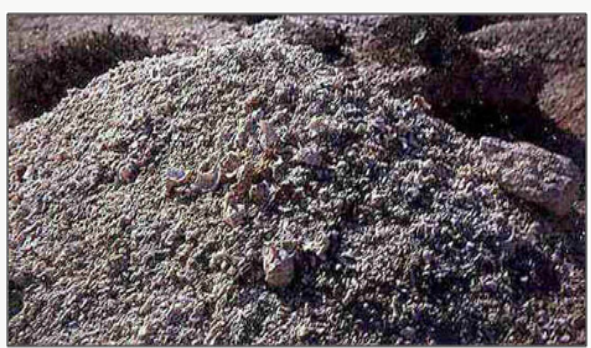

Figure 9: Piles of crushed Murex brandaris in Tyre.
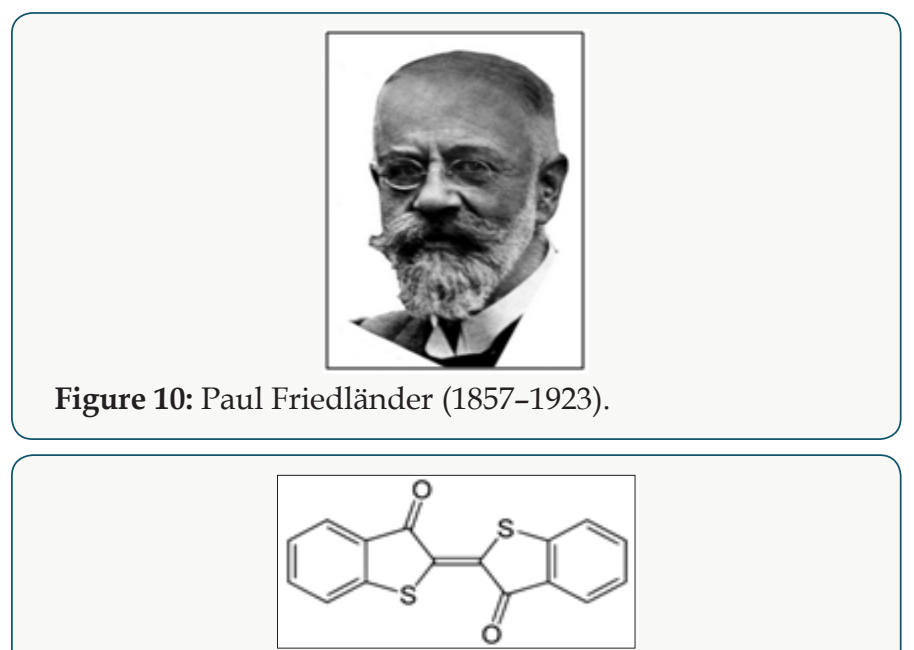

Figure 11: Thioindigo.

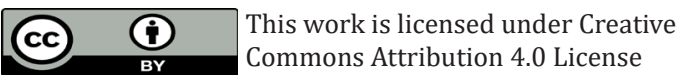

To Submit Your Article Click Here:

Submit Article

DOI: 10.32474/LTTFD.2018.01.000119<smiles>O=C1/C(=C2\Nc3cc(Br)ccc3C2=O)Nc2cc(Br)ccc21</smiles>

Figure 12: Tyran blue or Bromo Indigo.

\section{Discovery of Bromine}

Bromine was discovered in 1826, when the French chemist Antoine Balard (1802-1876) isolated it from chlorine. Its name was derived from the ancient Greek $\beta \rho \tilde{\omega} \mu$ os (bad smell) referring to its disagreeable smell. Bromine is a highly volatile reddish-brown liquid at room temperature. It is abundant in nature as bromide salts or as organobromine compounds, which are produced by many types or marine organisms. Sea water contains bromine in about 65ppm but bromine is found in much higher concentrations (2500 to $10,000 \mathrm{ppm}$ ) in inland seas and brine wells. The major areas of bromine production in the world are from salt brines found in the United Stated and China, from the Dead Sea in Israel and Jordan (Figure 13). Balard found bromine chemicals in the ash of seaweed from the salt marshes of Montpellier. The seaweed was used to produce iodine, but also contained bromine. Balard distilled the bromine from a solution of seaweed ash saturated with chlorine. Bromine was not produced in large quantities until 1858, when the discovery of salt deposits in Stassfurt enabled its production as a by-product of potash. Bromine present in minerals substituting for chlorine is very rare. Note that iodine is found in Chile nitrates in Salar de Atacama.

Figure 13: Antoine Balard (1802-1876).

\section{Conclusion}

While natural indigo occurs solely in plant kingdom, natural bromo-indigo occurs in Murex brandaris in the animal kingdom. Bromine was also discovered in sea weeds.

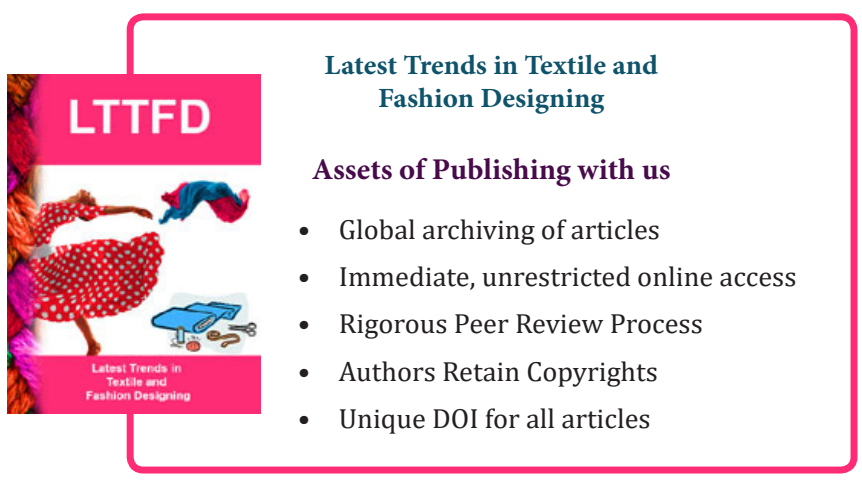

